\title{
COVID-19: The reaction of US oil and gas producers to the pandemic
}

\author{
Bernard Njindan lyke \\ ${ }^{1}$ Centre for Financial Econometrics, Deakin University, Melbourne, Australia \\ Keywords: volatility, stock returns, covid-19, oil and gas firms
}

\section{Energy RESEARCH LETTERS}

Vol. 1, Issue 2, 2020

\begin{abstract}
In this paper, we examine the reaction of US oil and gas producers to the COVID-19 pandemic. We find that firms react to COVID-19 heterogeneously. The pandemic significantly explains $28 \%$ of returns and $27 \%$ of return volatility. These findings are qualitatively consistent when using competing COVID-19 indicators.
\end{abstract}

\section{INTRODUCTION}

The COVID-19 pandemic-which is caused by severe acute respiratory syndrome coronavirus 2 (SARS-CoV-2)-has halted economic activities globally (Iyke \& Ho, 2020; Narayan, 2020; Phan \& Narayan, 2020). ${ }^{1}$ In this paper, we examine how oil and gas firms reacted to the COVID-19 pandemic. In theory, the impact of the COVID-19 pandemic on the oil and gas industry seems obvious. The disruption in demand vis-à-vis excess supply will lead, inter alia, to declines in oil and gas prices, supply, and firm revenues. ${ }^{2}$ Consistent with this possibility, Qin et al. (2020) show that the COVID-19 pandemic caused a reduction in oil demand leading to a decline in oil prices. Similarly, Gil-Alana and Monge (2020) find that the COVID-19 outbreak made the oil market inefficient, and, in turn, oil prices difficult to forecast. An alternative credible explanation is that the rate of COVID-19 infections and deaths created fear among investors, and this had implications for stock valuation. Pessimism about the future of the economy (or a negative investor sentiment) leads to a significant decline in trading activities, and stock prices. Chen, Chen, and Lee (2013) find that optimism causes overvaluation while pessimism causes undervaluation of industry returns. They note that the impact of sentiments may vary across stocks, consistent with theory. ${ }^{3}$ Liu, Wang, and Lee (2020), on the other hand, find that the COVID-19 pandemic had a positive impact on crude oil and stock returns.

What remains unclear is how individual firms in the oil and gas industry reacted to the COVID-19 pandemic, which we proxy using deaths per million (TDM). In this regard, we provide novel evidence on the firm-specific impact of the pandemic on returns of oil and gas firms. Our empirical analysis focuses on 90 US oil and gas firms for two reasons. First, these firms have consistent data as compared with oil and gas firms of other countries. Second, for several years now, the US consistently emerged as the top producer of oil and gas and based on the most current ranking, the country produced 19\% share of world total oil and gas (or $19.51 \mathrm{mil}-$ lion barrels per day) in $2019 .^{4}$
Using daily data over the period of 21 January 2020 to 5 May 2020, we unravel the following findings. First, the influence of COVID-19 on returns is statistically significant in $25 / 90$ firms (or $28 \%$ of the firms). Second, COVID-19 can significantly explain return volatility in $24 / 90$ firms (or $27 \%$ of the firms). Third, firms return and volatility react to COVID-19 heterogeneously. The effect varies from negative to positive, suggesting that the reaction of the oil and gas stocks to the pandemic is firm-specific. In fact, some stocks do not show a statistically significant reaction to the pandemic at all. Our results are qualitatively consistent when using alternative measures of COVID-19 and controlling for the Russia-Saudi Arabia oil price war of May to April 2020. Narayan and Sharma (2011) show that turnover rate and size dictate firms' reaction to oil prices. They show, for instance, that larger firms tend to react negatively to oil price increase, while smaller firms tend to react positively. Our finding could be driven by the turnover rate and size effects, which we do not explore. We leave this aspect of research to future studies.

Our contribution relates to the effect of COVID-19 on returns and volatility-this aspect is less understood given that the pandemic-based research is at a nascent stage. Ali et al. (2020), Phan and Narayan (2020) and Liu, Wang, and Lee (2020), for instance, study this issue but focus on aggregate stock market reaction to COVID-19. Studies, such as Gil-Alana and Monge (2020), Narayan (2020), and Qin et al. (2020), examine the effect of the pandemic on oil prices, while others, such as Iyke (2020), examine the effect of the pandemic on foreign exchange markets. We add to these studies on COVID-19 and the financial system by showing how the pandemic has influenced firm returns and return volatility for a representative sample of 90 US oil and gas firms.

The paper proceeds as follows. Section II presents the data and results. Section III concludes the paper.

\section{DATA AND RESULTS}

We collect daily COVID-19 data on the total number of

\footnotetext{
1 See https://www.who.int/emergencies/diseases/novel-coronavirus-2019/technical-guidance/naming-the-coronavirus-disease(covid-2019)-and-the-virus-that-causes-it for the naming of the disease.

2 See also Iyke (2019), for a related explanation.

3 See Baker and Wurgler (2006) for the theoretical exposition.

4 This information is available at the Energy Information Administration's website at https://www.eia.gov/todayinenergy/detail.php?id=40973 and https://www.eia.gov/tools/faqs/faq.php?id=709\&t=6.
} 
deaths per million (TDM) from Our World in Data. ${ }^{5}$ We retrieve the stock data for each of the 90 US oil and gas producers from https://finance.yahoo.com/. The 90 US oil and gas producers are chosen following the guidance provided by https://money.usnews.com/investing/stocks/oil-gasproduction; the complete list can be found at this link and is available upon request. Using the daily closing price $(C P)$, we calculate stock returns as $S R_{t}=\left[\ln \left(C P_{t}\right)-\ln \left(C P_{t-1}\right)\right] * 100$, where $\ln$ is the logarithm operator. The sample period is from 21 January 2020 to 5 May 2020.

Our preliminary analysis suggests that seven out of the 90 oil and gas firms (or $8 \%$ of the firms) recorded positive stock returns, while the remaining 83 firms (or 92\% of the firms) recorded negative stock returns during the COVID-19 outbreak. ${ }^{6}$ Those seven firms recorded an average stock return of $0.30 \%$ whereas the other 83 firms recorded an average return of $-0.97 \%$. Based on the skewness, kurtosis, and Jarque-Bera statistics, we find that stock returns and the COVID-19 indicators are non-normally distributed. We find evidence of unit roots for the COVID-19 indicators but not for stock returns. This does not rule out persistency in stock returns. In fact, the autoregressive coefficient of order one $(A R(1))$ indicates that 22/90 stock returns are persistent. Both the ADF and the AR(1) test results show that the COVID-19 indicators are highly persistent. Finally, the AR conditional heteroskedasticity (ARCH) effect test results suggest evidence of "ARCH" effects in 7/90 returns.

In theory, several factors can predict stock returns and return volatility. The external habit formation theories, for instance, emphasize that stock returns and volatility are determined by the surplus consumption ratio (Corradi et al., 2013). Consistent with theory, the commonly utilized determinants of stock returns and return volatility are interest rates, dividend yields, and consumption-wealth ratio (see Iyke \& Ho, 2020). From the sentiment literature (see Baker \& Wurgler, 2006), we learn that waves of sentiment influence cross-sectional returns. Consistent with this view, Narayan (2019) demonstrates that positive and negative oil news predict stock returns in 12 countries via the discount rate channel. Similarly, Narayan (2020) shows that positive and negative oil news and COVID-19 information can predict oil prices. Our argument is that the negative sentiments around the COVID-19 pandemic-the fear and panic it created-should have affected stock returns and volatility. Our argument is in line with the sentiment theory and evidence of stock price discovery. However, the role of pandemics in shaping stock returns and volatility is not yet analysed by the literature. In response, a growing literature now focuses on pandemics as a competing determinant of stock returns and volatility (Ali et al., 2020; Liu et al., 2020).

Our framework is motivated by the sentiment-stock return literature. We control for persistency and heteroskedasticity of returns, consistent with Iyke and Ho (2020). Financial markets are known to react to news asymmetrically (Iyke, 2020). For example, Iyke and Ho (2019) show that negative news induces higher volatility as compared with positive news. To model this attribute of financial markets, as well as the features of our data, we use the exponential generalised ARCH (EGARCH) model. Specifically, we fit the following $\operatorname{EGARCH}(1,1)$ model:

$$
S R_{t}=\gamma_{0}+\gamma_{1} S R_{t-1}+\gamma_{2} \Delta T D M_{t}+\epsilon_{t}
$$

where $\triangle T D M$ is the first difference of $T D M$, to remove unit roots in this variable; $\gamma_{i}$ are parameters of the mean equation; and $\epsilon_{t}$ is the error term whose conditional variance, $\sigma_{t}^{2}$, takes the following form

$$
\ln \sigma_{t}^{2}=\bar{\rho}+\alpha_{1} \ln \sigma_{t-1}^{2}+\beta_{1}\left|\frac{\varepsilon_{t-1}}{\sigma_{t-1}}\right|+\tau_{1} \frac{\varepsilon_{t-1}}{\sigma_{t-1}}+\delta \Delta T D M_{t}
$$

where $\bar{\rho}, \alpha_{1}, \beta_{1}, \tau_{1}$, and $\delta$ are parameters; In and $\|$ are the natural logarithm and absolute value operators, respectively.

Table 1, which reports estimates from Eqs. (1) and (2), shows that COVID-19 influences stock returns of oil and gas firms. In 25/90 firms (or $28 \%$ of the firms) the effect on returns is statistically significant. Similarly, the estimates show that COVID-19 significantly explains return volatility in $24 / 90$ firms (or $27 \%$ of the firms). A careful look at the estimates suggests that the impact of COVID-19 on return and its volatility are heterogenous across the oil and gas firms, varying from negative to positive. That is, the oil and gas stocks react differently to the pandemic. Some stocks do not show a statistically significant reaction to the pandemic. In their study, Narayan and Sharma (2011) find that size and turnover rate explain the different responses of firms to changes in oil prices. For example, they find that smaller firms respond positively to oil price increases whereas larger firms respond negatively. In our framework, firm turnover rate and size may be driving the heterogenous reaction of returns and volatility to the COVID-19 pandemic, which we do not explore. Future studies should explore these effects.

We perform three sets of robustness tests and withhold the test results to conserve space. First, we control for the Russia-Saudi Arabia oil price war of 8 March 2020-which crashed oil prices by $30 \%$ and remains the biggest one-day decline in oil prices since the Gulf war (Raval \& Sheppard, 2020). To capture this, we introduce in Equations (1) and (2) a dummy variable, which equals one from 8 March to 12 April 2020 and zero otherwise. ${ }^{7}$ The estimates suggest that COVID-19 can explain 30/90 (or 33\%) and $47 / 90$ (or 52\%) of firm returns and return volatility, respectively. Thus, the pandemic explains returns and volatility better when the relation between returns and COVID-19 is modelled by controlling the oil price war.

Second, we replicate the analysis by measuring the COVID-19 pandemic using the total number of daily deaths, TD. The estimates suggest that COVID-19 can explain 20/ 90 (or $22 \%$ ) and 30/90 (or 33\%) of firm returns and return volatility, respectively. Third, we repeat the estimation using the total daily number of deaths per million population for the entire world from COVID-19. These estimates suggest that the impact of COVID-19 is statistically significant for $24 / 90$ (or $27 \%$ ) firm returns and for $24 / 90$ (or $27 \%$ ) return volatility. Overall, these results are qualitatively consistent when using the two competing COVID-19 indicators.

\section{CONCLUSION}

In this study, we examine the reaction of US oil and gas firms to the COVID-19 pandemic. We found a heterogenous reaction of firms to COVID-19. The pandemic significantly explains $28 \%$ of returns and $27 \%$ of return volatility. We

\footnotetext{
5 The data is available here https://ourworldindata.org/coronavirus-source-data.

6 The summary statistics are withheld due to space consideration and are available upon request.

7 The Russia-Saudi Arabia oil price war ended on 12 April 2020 (Raval \& Sheppard, 2020).
} 
Table 1: Stock return and volatility reaction to total deaths per million from COVID-19

\begin{tabular}{|c|c|c|c|c|}
\hline Company (Stock) & Mean equation & $p$-value & Variance equation & $p$-value \\
\hline USEG & 0.050 & 0.490 & -0.008 & 0.161 \\
\hline CEI & 0.003 & 0.975 & -0.049 & 0.199 \\
\hline $\mathrm{CHK}$ & -0.055 & 0.835 & 0.009 & 0.222 \\
\hline MCEP & -0.166 & 0.092 & 0.000 & 0.993 \\
\hline ovV & 0.456 & 0.054 & 0.073 & 0.343 \\
\hline MCF & 0.195 & 0.319 & 0.015 & 0.269 \\
\hline CRK & 0.250 & 0.003 & -0.110 & 0.026 \\
\hline HES & 0.170 & 0.127 & 0.000 & 0.983 \\
\hline CEO & 0.093 & 0.034 & -0.008 & 0.412 \\
\hline SWN & 0.209 & 0.237 & -0.027 & 0.698 \\
\hline$M \times C$ & 0.102 & 0.452 & -0.008 & 0.263 \\
\hline CNQ & -0.008 & 0.906 & 0.019 & 0.130 \\
\hline COP & 0.008 & 0.921 & 0.028 & 0.062 \\
\hline BCEI & -0.008 & 0.927 & 0.006 & 0.674 \\
\hline DMLP & 0.129 & 0.239 & 0.019 & 0.460 \\
\hline EPSN & 0.037 & 0.021 & -0.018 & 0.000 \\
\hline RRC & 0.438 & 0.002 & -0.008 & 0.333 \\
\hline NRT & 0.206 & 0.153 & -0.010 & 0.056 \\
\hline EQT & 0.215 & 0.045 & -0.004 & 0.896 \\
\hline $\mathrm{ZN}$ & 0.121 & 0.101 & -0.110 & 0.035 \\
\hline PXD & 0.185 & 0.017 & 0.123 & 0.003 \\
\hline SBR & 0.029 & 0.714 & 0.001 & 0.937 \\
\hline HUSA & 0.119 & 0.496 & 0.075 & 0.085 \\
\hline CRT & 0.197 & 0.078 & -0.012 & 0.153 \\
\hline EOG & -0.095 & 0.000 & 0.059 & 0.045 \\
\hline PNRG & -0.059 & 0.589 & -0.002 & 0.859 \\
\hline WTI & 0.246 & 0.002 & -0.003 & 0.838 \\
\hline TGC & 0.038 & 0.632 & -0.011 & 0.196 \\
\hline CVE & 0.035 & 0.797 & 0.012 & 0.149 \\
\hline CXO & 0.021 & 0.807 & 0.022 & 0.259 \\
\hline GPRK & -0.050 & 0.472 & -0.003 & 0.850 \\
\hline EGY & 0.049 & 0.575 & 0.003 & 0.741 \\
\hline MR & 0.465 & 0.030 & 0.062 & 0.375 \\
\hline MUR & 0.175 & 0.086 & 0.012 & 0.366 \\
\hline MGY & 0.240 & 0.211 & 0.007 & 0.662 \\
\hline WPX & 0.069 & 0.614 & 0.019 & 0.679 \\
\hline MTR & -0.059 & 0.613 & -0.012 & 0.453 \\
\hline PE & -0.061 & 0.509 & 0.032 & 0.093 \\
\hline EPM & 0.130 & 0.237 & 0.005 & 0.787 \\
\hline GBR & -0.045 & 0.825 & -0.025 & 0.000 \\
\hline DVN & 0.100 & 0.509 & 0.012 & 0.394 \\
\hline BSM & 0.077 & 0.594 & -0.008 & 0.384 \\
\hline NOG & 0.107 & 0.218 & -0.003 & 0.789 \\
\hline VOC & 0.039 & 0.767 & 0.150 & 0.042 \\
\hline BRY & 0.238 & 0.177 & 0.007 & 0.663 \\
\hline CPG & 0.113 & 0.397 & 0.020 & 0.126 \\
\hline NBL & 0.060 & 0.647 & 0.020 & 0.179 \\
\hline
\end{tabular}




\begin{tabular}{|c|c|c|c|c|}
\hline Company (Stock) & Mean equation & $p$-value & Variance equation & $p$-value \\
\hline BRN & 0.111 & 0.226 & -0.203 & 0.000 \\
\hline MTDR & 0.227 & 0.083 & 0.027 & 0.083 \\
\hline APA & 0.060 & 0.622 & 0.019 & 0.350 \\
\hline XEC & 0.140 & 0.243 & 0.002 & 0.882 \\
\hline FANG & 0.150 & 0.295 & -0.005 & 0.590 \\
\hline MRO & 0.144 & 0.362 & 0.126 & 0.010 \\
\hline AR & 0.749 & 0.009 & 0.035 & 0.605 \\
\hline ENSV & -0.091 & 0.490 & 0.026 & 0.000 \\
\hline CLR & 0.422 & 0.005 & 0.062 & 0.443 \\
\hline PDCE & 0.007 & 0.955 & 0.006 & 0.778 \\
\hline ERF & 0.206 & 0.024 & 0.010 & 0.418 \\
\hline OXY & 0.087 & 0.222 & 0.005 & 0.727 \\
\hline FLNG & 0.172 & 0.119 & -0.010 & 0.242 \\
\hline ECT & 0.206 & 0.045 & 0.019 & 0.075 \\
\hline PHX & 0.043 & 0.753 & 0.009 & 0.602 \\
\hline PER & -0.055 & 0.580 & -0.001 & 0.940 \\
\hline TGA & 0.021 & 0.838 & 0.011 & 0.602 \\
\hline VET & 0.080 & 0.593 & 0.009 & 0.402 \\
\hline KOS & 0.295 & 0.121 & -0.005 & 0.433 \\
\hline SBOW & 0.250 & 0.226 & 0.029 & 0.505 \\
\hline LPI & 0.651 & 0.000 & 0.109 & 0.061 \\
\hline NEXT & 0.045 & 0.492 & -0.011 & 0.448 \\
\hline SM & 0.469 & 0.023 & -0.005 & 0.654 \\
\hline GPOR & 0.678 & 0.002 & 0.011 & 0.677 \\
\hline REI & 0.596 & 0.001 & 0.155 & 0.035 \\
\hline ROYT & 0.072 & 0.554 & -0.020 & 0.415 \\
\hline LLEX & -0.036 & 0.728 & -0.063 & 0.421 \\
\hline SD & 0.395 & 0.000 & 0.214 & 0.000 \\
\hline PVAC & 0.528 & 0.007 & 0.032 & 0.415 \\
\hline LONE & 0.106 & 0.504 & -0.003 & 0.908 \\
\hline DNR & -0.174 & 0.305 & 0.033 & 0.014 \\
\hline BTE & -0.042 & 0.658 & 0.026 & 0.134 \\
\hline HPR & 0.274 & 0.113 & 0.008 & 0.493 \\
\hline GTE & 0.157 & 0.425 & -0.002 & 0.766 \\
\hline QEP & -0.095 & 0.542 & 0.052 & 0.000 \\
\hline OAS & 0.001 & 0.996 & 0.065 & 0.187 \\
\hline CPE & -0.102 & 0.249 & -0.080 & 0.162 \\
\hline CDEV & 1.058 & 0.000 & -0.029 & 0.000 \\
\hline XOG & 0.140 & 0.497 & -0.003 & 0.849 \\
\hline CRC & 0.053 & 0.462 & 0.063 & 0.000 \\
\hline WLL & 0.106 & 0.315 & -0.080 & 0.043 \\
\hline CHAP & 0.164 & 0.558 & -0.002 & 0.909 \\
\hline UNT & 0.079 & 0.687 & -0.001 & 0.988 \\
\hline
\end{tabular}

The table shows estimates of the EGARCH(1,1) model: $S R_{t}=\gamma_{0}+\gamma_{1} S R_{t-1}+\gamma_{2} \Delta T D M_{t}+\epsilon_{t}$, where $\Delta T D M$ is the first difference of $T D M$; $\gamma_{i}$ are parameters of the mean equation; and $\epsilon_{t}$ is the error term whose conditional variance, $\sigma_{t}^{2}$, takes the form $\ln \sigma_{t}^{2}=\bar{\rho}+\alpha_{1} \ln \sigma_{t-1}^{2}+\beta_{1}\left|\frac{\varepsilon_{t-1}}{\sigma_{t-1}}\right|+\tau_{1} \frac{\varepsilon_{t-1}}{\sigma_{t-1}}+\delta \Delta T D M_{t}$, where $\bar{\rho}, \alpha_{1}, \beta_{1}, \tau_{1}$, and $\delta$ are parameters; ln and $\|$ are the natural logarithm and absolute value operators, respectively. In the mean and variance equations, we report the coefficients, $\gamma_{2}$ and $\delta$, and their $p$-values. The sample is from 21 January 2020 to 5 May 2020. 
demonstrate that our findings survive robustness tests. The heterogeneous reaction of firms could be driven by firmspecific attributes, such as size and turnover rate, which we did not model. Future studies could extend our study by analysing the role of these attributes in explaining the heterogeneous reaction of firms to COVID- 19 .

\section{ACKNOWLEDGMENT}

This research is supported by Deakin University through the DUPR/RTP Funds.

The author would like to acknowledge the comments provided by the editor and an anonymous referee, which has helped in improving this paper.

This is an open-access article distributed under the terms of the Creative Commons Attribution 4.0 International License (CCBY-SA-4.0). View this license's legal deed at https://creativecommons.org/licenses/by-sa/4.0 and legal code at https://creativecommons.org/licenses/by-sa/4.0/legalcode for more information. 


\section{REFERENCES}

Ali, M., Alam, N., \& Rizvi, S. A. R. (2020). Coronavirus (COVID-19) - An epidemic or pandemic for financial markets. Journal of Behavioral and Experimental Finance, 27, 100341. https://doi.org/10.1016/j.jbef.20 $\underline{20.100341}$

Baker, M., \& Wurgler, J. (2006). Investor Sentiment and the Cross-Section of Stock Returns. The Journal of Finance, 61(4), 1645-1680. https://doi.org/10.111 $1 / \mathrm{j} .1540-6261.2006 .00885 . \mathrm{x}$

Chen, M.-P., Chen, P.-F., \& Lee, C.-C. (2013). Asymmetric effects of investor sentiment on industry stock returns: Panel data evidence. Emerging Markets Review, 14, 35-54. https://doi.org/10.1016/j.emema r.2012.11.001

Corradi, V., Distaso, W., \& Mele, A. (2013).

Macroeconomic determinants of stock volatility and volatility premiums. Journal of Monetary Economics, 60(2), 203-220. https://doi.org/10.1016/j.jmoneco.20 12.10 .019

Gil-Alana, L. A., \& Monge, M. (2020). Crude oil prices and COVID-19: Persistence of the shock. Energy Research Letters, 1(1), 13200. https://doi.org/10.4655 7/001c.13200

Iyke, B. N. (2019). Real output and oil price uncertainty in an oil producing country. Buletin Ekonomi Moneter dan Perbankan, 22(2), 163-176. htt ps://doi.org/10.21098/bemp.v22i2.1095

Iyke, B. N. (2020). The disease outbreak channel of exchange rate return predictability: Evidence from COVID-19. Emerging Markets Finance and Trade. In press. https://doi.org/10.1080/1540496X.2020.178471 $\underline{8}$

Iyke, B. N., \& Ho, S. Y. (2019). Consumption and exchange rate uncertainty: Evidence from selected Asian countries. The World Economy. https://doi.org/ 10.1111/twec. 12900
Iyke, B. N., \& Ho, S. Y. (2020). Stock return predictability over four centuries: The role of commodity returns. Working Paper.

Liu, L., Wang, E. Z., \& Lee, C. C. (2020). Impact of the COVID-19 pandemic on the crude oil and stock markets in the US: A time-varying analysis. Energy Research Letters, 1(1), 13154. https://doi.org/10.4655 7/001c.13154

Narayan, P. K. (2019). Can stale oil price news predict stock returns? Energy Economics, 83, 430-444. http s://doi.org/10.1016/i.eneco.2019.07.022

Narayan, P. K. (2020). Oil price news and COVID-19-Is there any connection? Energy Research Letters, 1(1), 13176. https://doi.org/10.46557/001c.13176

Narayan, P. K., \& Sharma, S. S. (2011). New evidence on oil price and firm returns. Journal of Banking \& Finance, 35(12), 3253-3262. https://doi.org/10.1016/ j.jbankfin.2011.05.010

Phan, D. H. B., \& Narayan, P. K. (2020). Country responses and the reaction of the stock market to COVID-19-A preliminary exposition. Emerging Markets Finance and Trade. In press.

Qin, M., Zhang, Y. C., \& Su, C. W. (2020). The Essential Role of Pandemics: A Fresh Insight into the Oil Market. Energy Research Letters, 1(1), 13166. http s://doi.org/10.46557/001c.13166

Raval, A., \& Sheppard, D. (2020). Oil crash: Why Saudi Arabia has started a global crude price war. Financial Times. https://www.ft.com/content/59dcba 56-61a2-11ea-b3f3-fe4680ea68b5 


\section{FIGURES, TABLES, AND SUPPLEMENTARY MATERIALS}

\section{Dataset}

Download: https://erl.scholasticahq.com/article/13912-covid-19-the-reaction-of-us-oil-and-gas-producers-to-thepandemic/attachment/38750.zip 